\title{
3D Ultrasound for Imaging and Quantifying Carotid Ulcers
}

$I^{n+\infty}$

$\mathrm{n}$ their recent article, Yuan et $\mathrm{al}^{1}$ stated that they "highlight the merits and limitations of various imaging techniques for identifying carotid plaque ulceration." It is curious, therefore, that they made no mention of 3D sonography (3DUS). Although ulceration seen on angiography predicted risk in the North American Symptomatic Carotid Endarterectomy Trial, ${ }^{2}$ it was clear that imaging of the lumen by angiography was not a reliable way to assess ulceration. ${ }^{3}$

Schminke et $\mathrm{al}^{4}$ reported that 3DUS was a better way to image ulceration than 2D sonography. In 2011, we reported that the number of carotid ulcers (Fig 1) was as strong a predictor of risk among patients with asymptomatic carotid stenosis; patients with $\geq 3$ ulcers in either carotid artery had a risk equivalent to that of patients with microemboli on transcranial Doppler sonography. ${ }^{5}$

In 2104, we reported that ulcer volume predicted cardiovascular risk among patients attending cardiovascular prevention clinics (Fig 2). ${ }^{6}$ It is likely that the best way to image and quantify carotid ulceration is with 3DUS.

Disclosures: J. David Spence-UNRELATED: Other: Dr Spence is an officer of Vascularis Inc.

http://dx.doi.org/10.3174/ajnr.A5130

\section{REFERENCES}

1. Yuan J, Usman A, Das T, et al. Imaging carotid atherosclerosis plaque ulceration: comparison of advanced imaging modalities and recent developments. AJNR Am J Neuroradiol 2016 Dec 22. [Epub ahead of print] CrossRef Medline

2. Eliasziw M, Streifler JY, Fox AJ, et al. Significance of plaque ulceration in symptomatic patients with high-grade carotid stenosis: North American Symptomatic Carotid Endarterectomy Trial. Stroke 1994; 25:304-08 CrossRef Medline

3. Streifler JY, Eliasziw M, Fox AJ, et al. Angiographic detection of carotid plaque ulceration: comparison with surgical observations in a multicenter study - North American Symptomatic Carotid Endarterectomy Trial. Stroke 1994;25:1130-32 CrossRef Medline

4. Schminke U, Motsch L, Hilker L, et al. Three-dimensional ultrasound observation of carotid artery plaque ulceration. Stroke 2000;31:1651-55 CrossRef Medline

5. Madani A, Beletsky V, Tamayo A, et al. High-risk asymptomatic carotid stenosis: ulceration on $3 \mathrm{D}$ ultrasound vs TCD microemboli. Neurology 2011;77:744-50 CrossRef Medline

6. Kuk M, Wannarong T, Beletsky V, et al. Volume of carotid artery ulceration as a predictor of cardiovascular events. Stroke 2014;45: 1437-41 CrossRef Medline

(D).D. Spence Stroke Prevention and Atherosclerosis Research Centre Robarts Research Institute Western University London, Ontario, Canada 

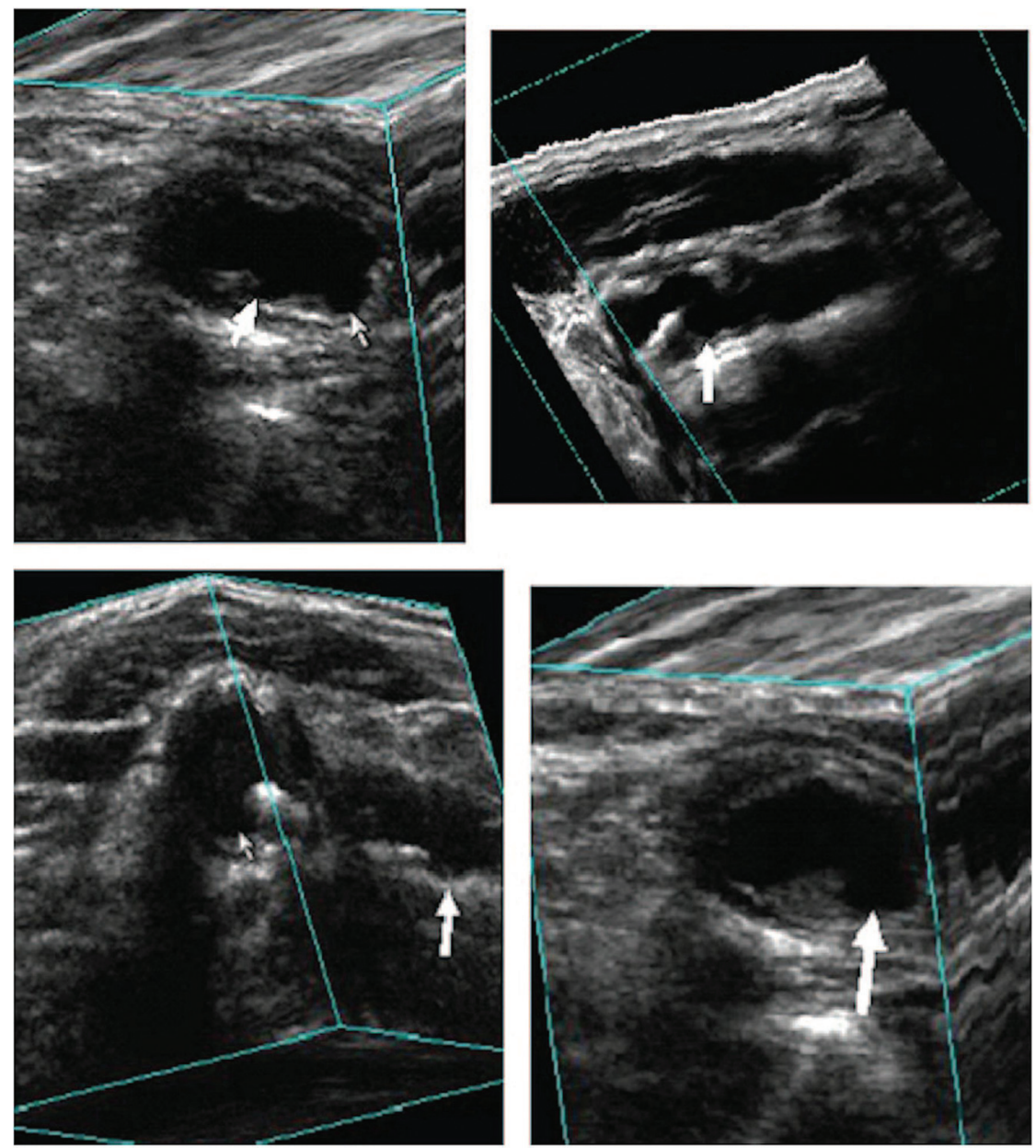

FIG 1. Number of carotid ulcers. The carotid artery can be examined in any axis for detection of ulcers in atherosclerotic plaques. White arrows show ulcers. Reproduced with permission of Wolters Kluwer from Madani et al. ${ }^{5}$ 

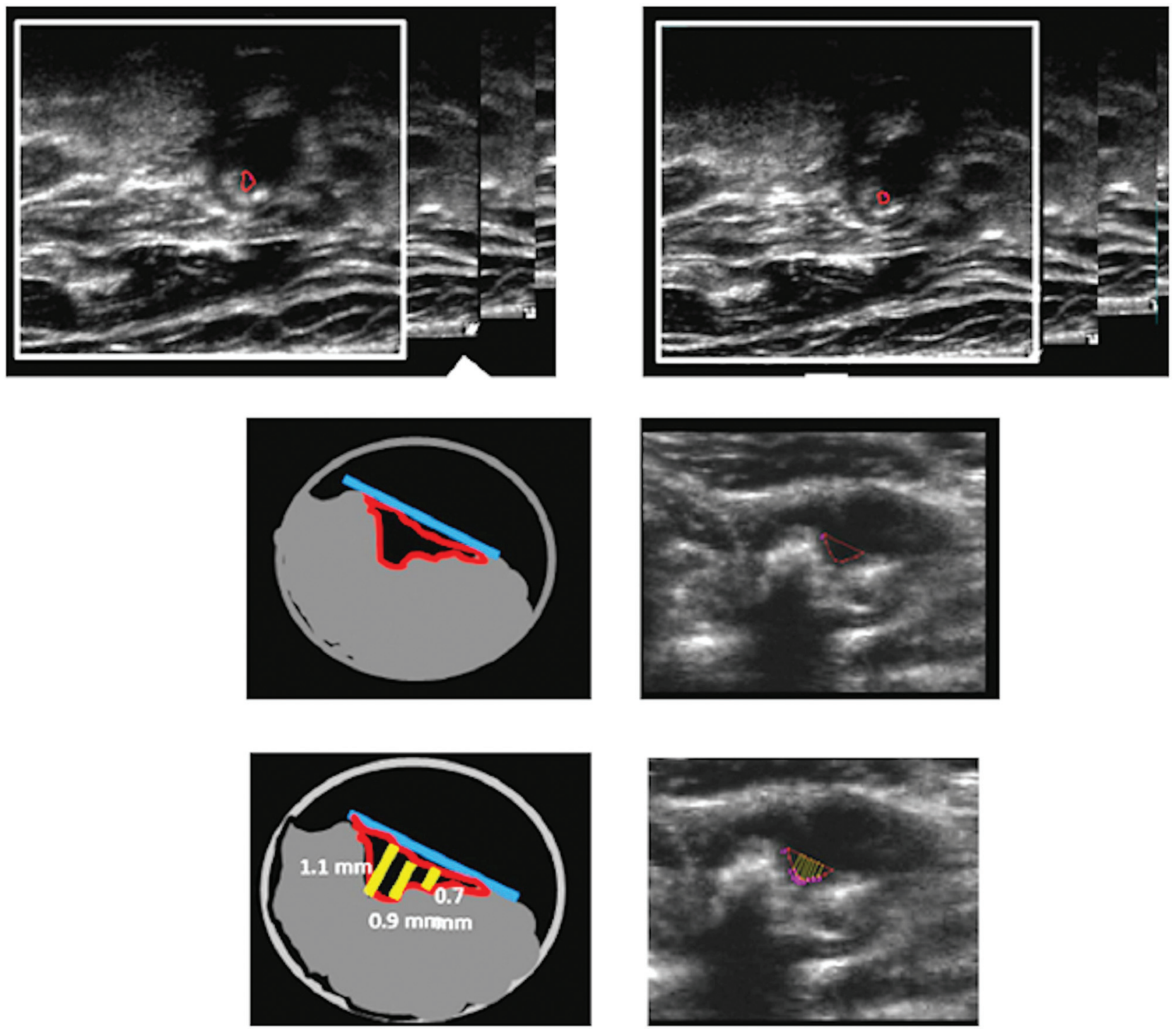

FIG 2. Measurement of ulcer volume and ulcer depth. Contours of ulcers were traced, and the depth of ulcers was measured in cross-sectional views. Each section had a thickness of $1 \mathrm{~mm}$; ulcer volume was computed from the sum of the volumes of all sections in which ulceration was traced. Reproduced with permission of Wolters Kluwer from Kuk et al. ${ }^{6}$ 